\title{
PHOTOELECTRON SPECTRA OF FLUORINE-SUBSTITUTED DIAZABENZENES
}

D. M. W. VAN DEN HAM, D. VAN DER MEER and D. FEIL Chemical Physics Laboratory, Twente University of Technology, Enschede (The Netherlands) (First received 7 February 1974; in final form 12 March 1974)

\section{ABSTRACT}

The high resolution $\mathrm{He} 584 \AA$ photoelectron spectra of ten fluorine-substituted diazabenzenes are presented. By means of fluorine substitution the analysis of the photoelectron spectra of the parent compounds can be made more definite. "Lonepair" ionization potentials are shown to correlate well with data calculated by a modified and iterative version of the extended Huickel method.

\section{INTRODUCTION}

The replacement of hydrogen atoms in aromatic molecules by fluorine causes drastic changes in the electronic properties of such a molecule. As a rule the $\pi$ molecular orbitals (MO's) and the $\sigma$ MO's are differently affected. This phenomenon makes perfluorination an excellent means to discern between $\sigma$ and $\pi$ bands in photoelectron spectra (PE spectra). In this way the analysis of the PE spectra of e.g. naphthalene ${ }^{1}$ and pyridine ${ }^{1,2}$ have been settled.

Especially in the case of aza- and diazaaromatics, where nitrogen "Ione-pair" bands and $\pi$ bands lie in the same region of the spectrum, the use of the perfluoro effect is indispensable for a thorough analysis of the spectra. In previous contributions we reported the use of this effect in the analysis of the PE spectra of quinoline and isoquinoline ${ }^{3}$ and of some diazanaphthalenes ${ }^{4}$. In the case of diazaaromatics, fluorine substitution not only shifts $\sigma$ and $\pi$ MO's, but also influences the interaction between the nitrogen "lone-pair" orbitals. In the few cases that we investigated" this effect could be described with Hoffmann's ${ }^{5}$ through-space and through-bond coupling model. If this model has general validity, a consequence would be that fluorine substitution can give experimental evidence about the symmetry character of the nitrogen "lone-pair" MO's". Since symmetry plays a dominant role in these considerations, we investigated the highly symmetrical diazabenzenes and their fluorine derivatives. 


\section{METHODS AND RESULTS}

The spectra have been recorded on a Vacuum Generators spectrometer. All photoionizations have been brought about by irradiation with a He $584 \AA$ source. The spectra were calibrated with argon.

The spectra are presented in Figures 1-3. The spectra of the unsubstituted compounds have been published before ${ }^{6-8}$, but have been added for reasons of comparison.

The unsubstituted compounds were obtained from commercial sources and purified before use. The compounds: tetrafluoropyridazine, tetrafluoropyrazine,

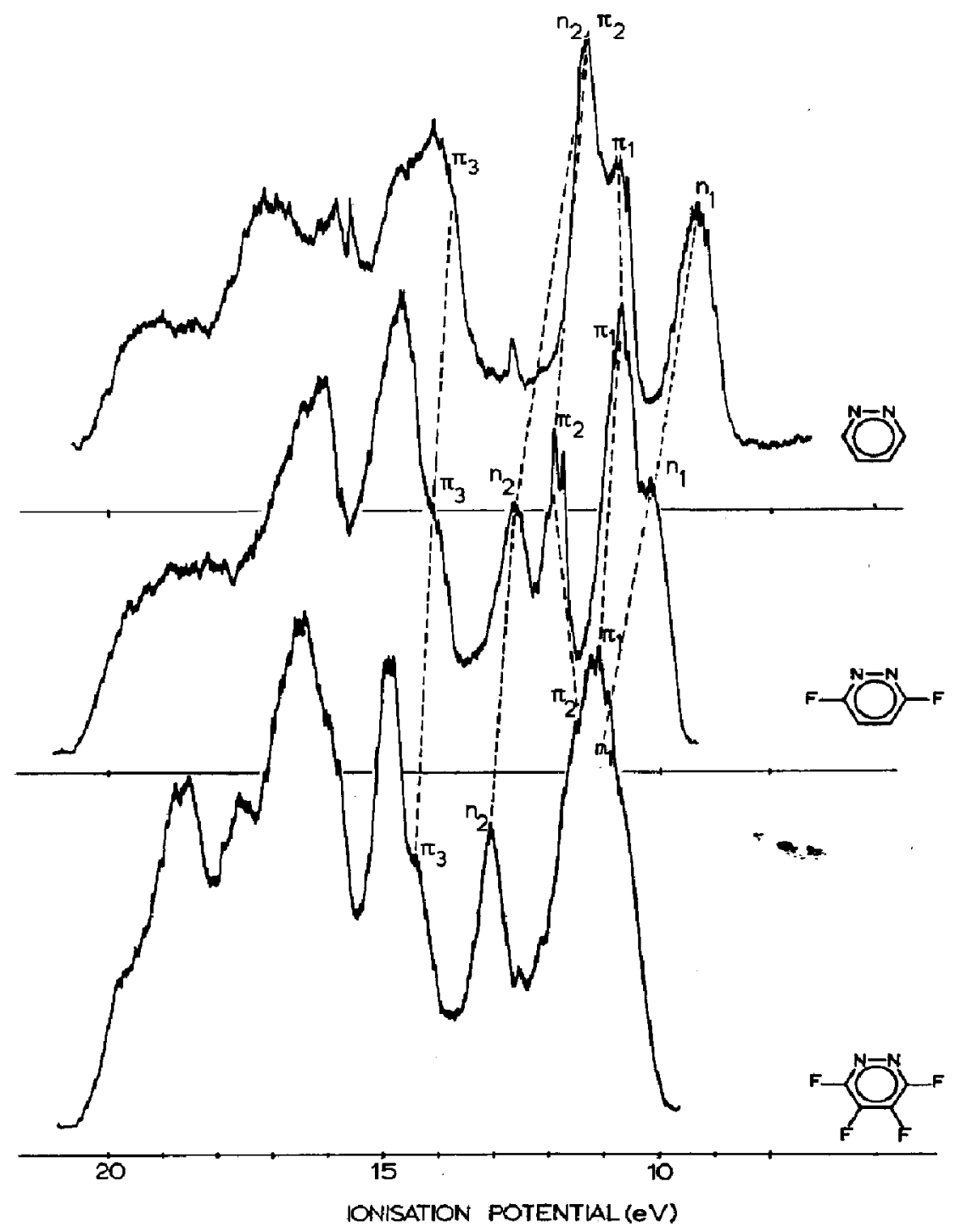

Figure 1. Photoelectron spectra of the pyridazine series. 


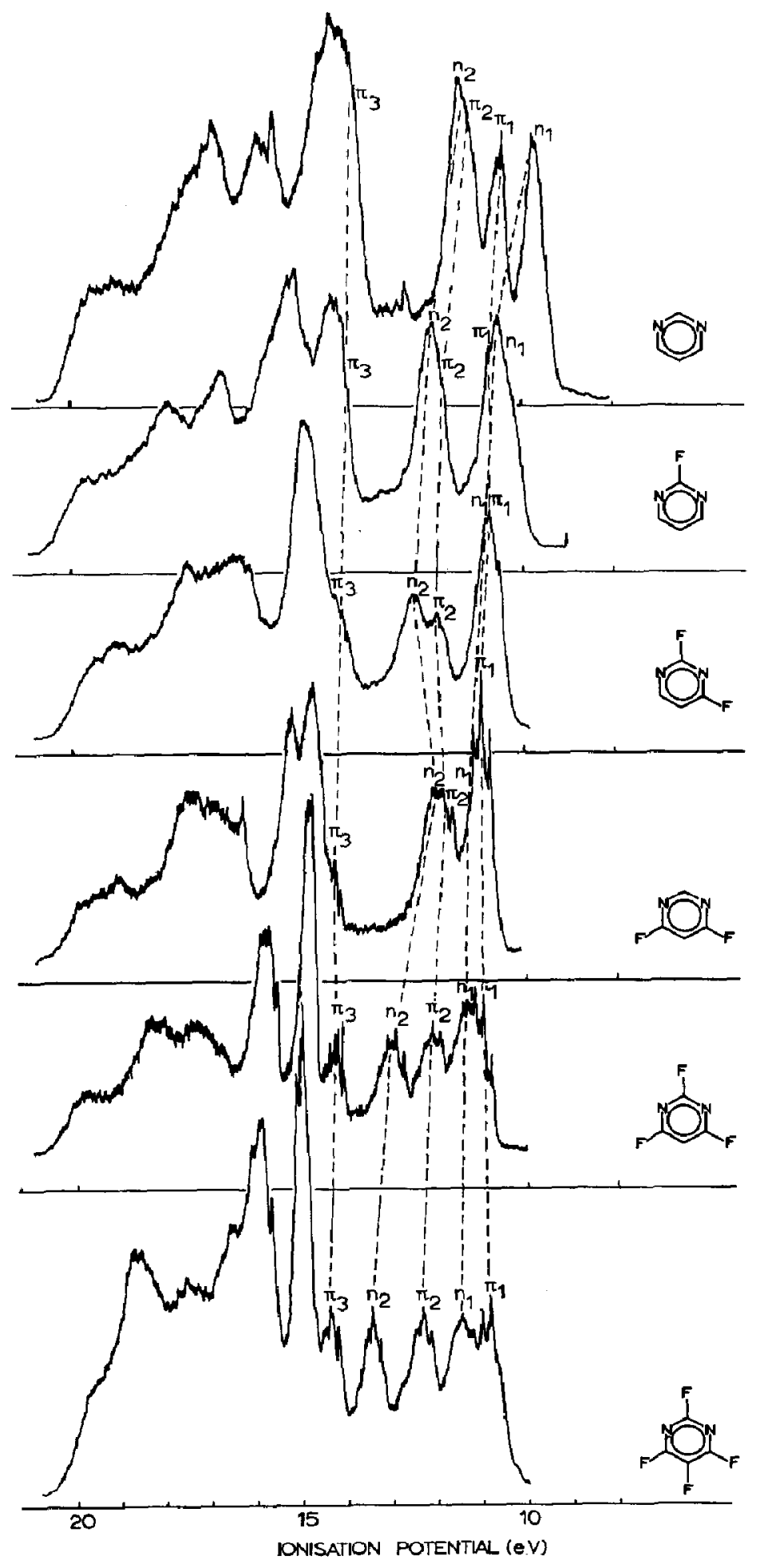

Figure 2. Photoelectron spectra of the pyrimidine series. 


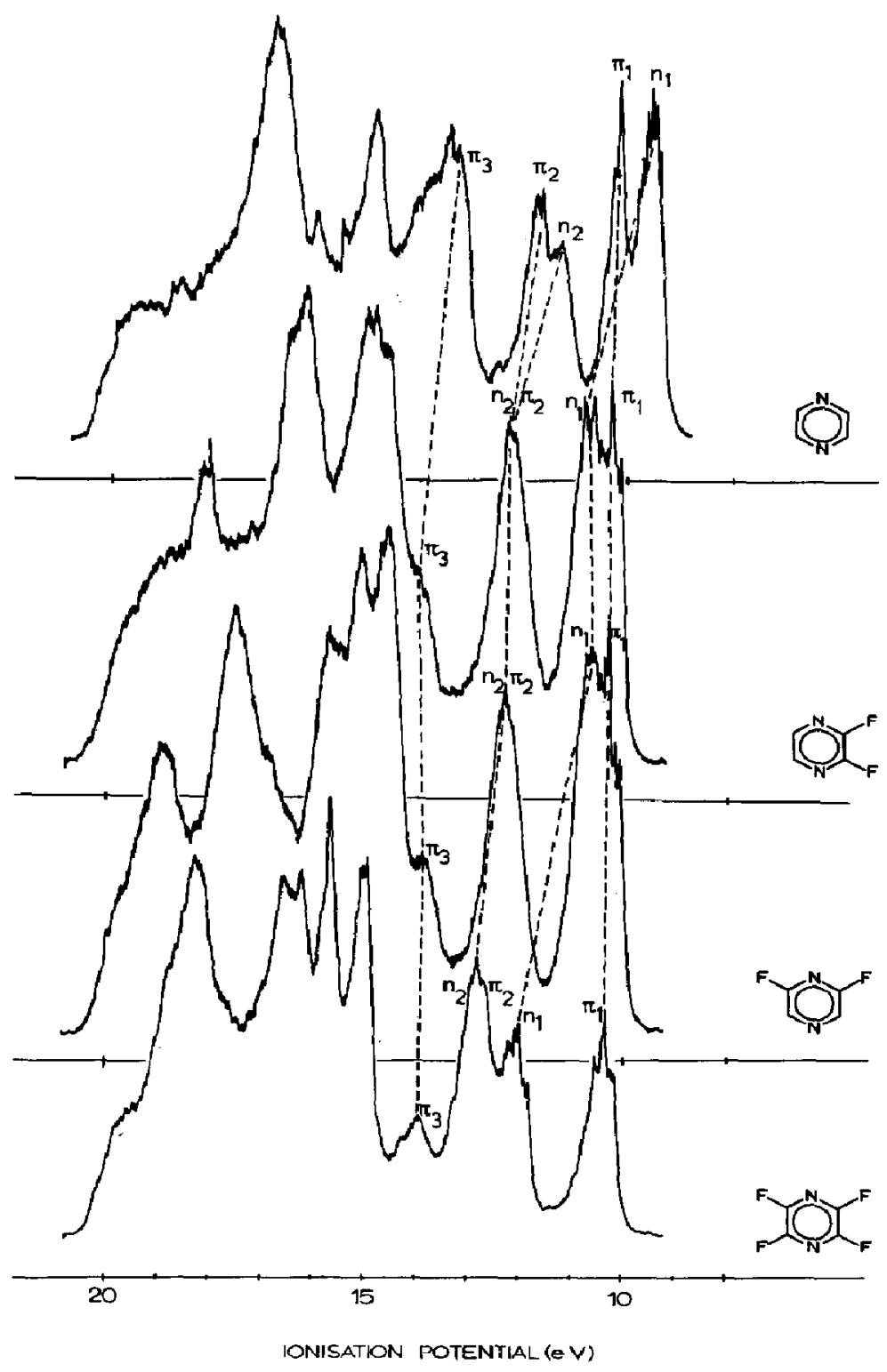

Figure 3. Photoelectron spectra of the pyrazine series.

tetrafluoropyrimidine and 2,4,6-trifluoropyrimidine have been synthesized according to the literature ${ }^{9-11}$. 2-Fluoropyrimidine was obtained by heating 2-chloropyrimidine with silver fluoride. The other compounds were prepared by heating the corresponding chlorine derivatives with dry potassium fluoride at temperatures ranging from $250^{\circ}$ to $300^{\circ} \mathrm{C}$.

The purity of all compounds was checked with gas liquid chromatography (g.l.c.). In some cases purification with g.l.c. on preparative scale was necessary. The compounds were identified by their mass spectrum and by elemental analysis. 


\section{DISCUSSION}

Analysis of the spectra

The analysis of the spectra of aza- and diazabenzenes has been carried out by several authors ${ }^{6-8}$. Although these assignments sometimes disagree, they nearly all have in common that bands in the spectral region of 9 to ca. $14 \mathrm{eV}$ are attributed to ionizations from $\pi$ or $\mathbf{n}$ type orbitals. In most cases the analysis is limited to that first part of the spectra; the obvious reason is that from $14 \mathrm{eV}$ on, the spectra become undecipherable due to the multitude of overlapping $\sigma$ bands. The assignment of PE bands to $\pi$ or $n$ ionization processes usually relies in part on the observation that bands that arise from the same type of orbital have comparable band shapes ${ }^{4,8}$, and in part on the correlation between experimental and calculated ionization potentials.

In our series of compounds, analysis is greatly facilitated by the fact that stepwise introduction of fluorine into the molecule causes relative small shifts in the position of the bands. By comparison of each spectrum with its "precursor", the consequence of the degree of fluorination on the band positions, can be followed.

Using these experimental tools, one is able to assign most of the bands with reasonable reliability to ionization from $\pi$ or $\mathbf{n}$ orbitals. We have designated our

TABLE 1

EXPERIMENTAL AND CALCULATED $\pi$ IONIZATION POTENTIALS (eV)

\begin{tabular}{|c|c|c|c|c|c|c|}
\hline \multirow[t]{2}{*}{ Compound } & \multicolumn{3}{|c|}{$\begin{array}{l}I P(\pi) \\
\text { experimental }\end{array}$} & \multicolumn{3}{|c|}{$\begin{array}{l}\text { IP }(\pi) \\
\text { Hückel a }\end{array}$} \\
\hline & $\pi_{1}$ & $\pi_{2}$ & $\pi_{3}$ & $\pi_{1}$ & $\pi_{2}$ & $\boldsymbol{\pi x}_{3}$ \\
\hline Pyridazine & $10.6^{\mathrm{a}}$ & $11.3^{\mathrm{a}}$ & $13.7^{\mathrm{a}}$ & 10.57 & 10.96 & 14.40 \\
\hline 3,6-Difluoropyridazine & 10.6 & 11.9 & 14.1 & 11.02 & 11.18 & 14.32 \\
\hline Tetrafluoropyridazine & (11) & (11.5) & (14.4) & 11.30 & 11.58 & 14.29 \\
\hline Pyrimidine & $10.41^{\mathrm{a}}$ & $11.35^{\mathrm{a}}$ & $(13.7)^{\mathrm{a}}$ & 10.40 & 11.40 & 14.25 \\
\hline 2-Fluoropyrimidine & $(10.6)$ & $(11.7)$ & 13.8 & 10.64 & 11.40 & 14.20 \\
\hline 2,4-Difluoropyrimidine & $(10.65)$ & 12.02 & (14.1) & 10.76 & 11.58 & 14.18 \\
\hline 4,6-Difluoropyrimidine & 10.95 & 11.65 & 14.2 & 10.67 & 11.72 & 14.19 \\
\hline 2,4,6-Trifluoropyrimidine & 10.93 & 12.10 & 14.25 & 10.92 & 11.72 & 14.16 \\
\hline Tetrafluoropyrimidine & 10.82 & 12.31 & 14.4 & 11.25 & 11.72 & 14.15 \\
\hline Pyrazine & $10.18^{\mathrm{a}}$ & $11.77^{\mathrm{a}}$ & $(13.5)^{\mathbf{a}}$ & 10.07 & 11.70 & 14.20 \\
\hline 2,3-Diffuoropyrazine & 10.35 & 12.35 & 13.9 & 10.59 & 11.81 & 14.15 \\
\hline 2,6-Difluoropyrazine & 10.30 & $(12.3)$ & 13.8 & 10.66 & 11.79 & 14.15 \\
\hline Tetrafluoropyrazine & 10.37 & $(12.6)$ & 14.05 & 11.08 & 11.91 & 14.12 \\
\hline
\end{tabular}

a Values taken from ref. 8.

b $\alpha=6.82 \mathrm{eV} ; \beta=3.25 \mathrm{eV}$. 
TABLE 2

EXPERIMENTAL AND CALCULATED "LONE-PAIR" IONIZATION POTENTIALS (eV)

\begin{tabular}{|c|c|c|c|c|c|c|}
\hline & Band & Experimental & MIEHM & $M E H M$ & $E H T$ & Symmetry \\
\hline \multirow[t]{2}{*}{ Pyridazine } & $\mathrm{n}_{1}$ & $9.31^{\mathrm{A}}$ & 11.66 & 12.64 & 12.23 & $\mathbf{B}_{\mathbf{2}}$ \\
\hline & $\mathrm{n}_{2}$ & $11.30^{\mathrm{a}}$ & 13.72 & 13.51 & 13.02 & $\mathbf{A}_{1}$ \\
\hline \multirow[t]{2}{*}{ 3,6-Difluoropyridazine } & $\mathbf{n}_{1}$ & 10.17 & 12.80 & 12.58 & 12.20 & $\mathbf{B}_{\mathbf{2}}$ \\
\hline & $\mathbf{n}_{2}$ & 12.69 & 14.96 & 15.34 & 14.08 & $\mathrm{~A}_{1}$ \\
\hline \multirow[t]{2}{*}{ Tetrafluoropyridazine } & $\mathbf{n}_{1}$ & (11.15) & 13.91 & 13.21 & 12.61 & $\mathbf{B}_{2}$ \\
\hline & $\mathrm{n}_{2}$ & 13.13 & 15.34 & 14.90 & 14.78 & $\mathbf{A}_{1}$ \\
\hline \multirow[t]{2}{*}{ Pyrimidine } & $\mathbf{n}_{1}$ & $9.73^{a}$ & 11.76 & 12.60 & 12.34 & $\mathbf{B}_{\mathbf{2}}$ \\
\hline & $\mathrm{n}_{2}$ & $11.25^{\mathrm{a}}$ & 12.79 & 13.80 & 13.13 & $\mathbf{A}_{1}$ \\
\hline \multirow[t]{2}{*}{ 2-Fluoropyrimidine } & $\mathbf{n}_{1}$ & $(10.5)$ & 12.34 & 12.67 & 12.33 & $\mathbf{B}_{2}$ \\
\hline & $\mathbf{n} \mathbf{2}$ & $(11.8)$ & 13.80 & 14.23 & 13.40 & $\mathbf{A}_{1}$ \\
\hline \multirow[t]{2}{*}{ 2,4-Difluoropyrimidine } & $\mathbf{n}_{1}$ & $(10.75)$ & 13.11 & 13.17 & 12.67 & - \\
\hline & $\mathbf{n}_{2}$ & 12.39 & 14.34 & 14.21 & 13.39 & - \\
\hline \multirow[t]{2}{*}{ 4,6-Difluoropyrimidine } & $\mathrm{n}_{1}$ & $(11.20)$ & 13.32 & 13.62 & 12.95 & $\mathbf{B}_{\mathbf{2}}$ \\
\hline & $\mathrm{n}_{2}$ & 11.90 & 13.88 & 13.71 & 13.10 & $\mathbf{A}_{1}$ \\
\hline \multirow[t]{2}{*}{ 2,4,6-Triffuoropyrimidine } & $\mathbf{n}_{1}$ & 11.27 & 13.85 & 13.61 & 12.95 & $\mathbf{B}_{2}$ \\
\hline & $\mathbf{n}_{\mathbf{z}}$ & 12.90 & 14.83 & 14.19 & 13.37 & $\mathbf{A}_{1}$ \\
\hline \multirow[t]{2}{*}{ Tetrafluoropyrimidine } & $\mathbf{n}_{1}$ & 11.46 & 14.25 & 13.54 & 12.89 & $\mathbf{B}_{\mathbf{2}}$ \\
\hline & $\mathrm{n}_{2}$ & 13.45 & 15.67 & 15.14 & 13.94 & $\mathbf{A}_{1}$ \\
\hline \multirow[t]{2}{*}{ Pyrazine } & $\mathbf{n}_{1}$ & $9.63^{\mathrm{a}}$ & 11.64 & 12.31 & 11.93 & $\mathbf{A g}_{\mathrm{g}}$ \\
\hline & $\mathbf{n}_{2}$ & $11.35^{\mathrm{a}}$ & 13.12 & 14.64 & 13.85 & $\mathbf{B}_{2 \mathbf{u}}$ \\
\hline \multirow[t]{2}{*}{ 2,3-Difluoropyrazine } & $\mathrm{n}_{1}$ & 10.80 & 13.14 & 12.84 & 12.26 & - \\
\hline & $\mathrm{n}_{2}$ & 12.36 & 14.43 & 14.64 & 13.84 & - \\
\hline \multirow[t]{2}{*}{ 2,6-Difluoropyrazine } & $\mathrm{n}_{1}$ & 10.62 & 13.14 & 12.84 & 12.30 & 一 \\
\hline & $\mathbf{n}_{2}$ & $(12.3)$ & 14.46 & 14.67 & 13.84 & - \\
\hline \multirow{2}{*}{ Tetrafiuoropyrazine } & $\mathrm{n}_{1}$ & 12.06 & 14.57 & 13.75 & 12.82 & $\mathbf{A}_{\mathbf{g}}$ \\
\hline & $\mathrm{n}_{2}$ & $(12.9)$ & 15.60 & 14.67 & 13.84 & $\mathbf{B}_{2 \mathbf{u}}$ \\
\hline
\end{tabular}

a Values taken from ref. 8.

assignments in the spectra (Figures 1-3) and collected the measured vertical ionization potentials in Tables 1 and 2. Overlap of bands may render accurate measurements impossible. In these cases the tabulated data are estimated and appear between brackets.

Although the analysis of each separate PE spectrum often remains questionable, comparison of the members of a series of molecules with an increasing amount of substituted fluorine, excludes any doubt. In all diazabenzenes Gleiter et al. ${ }^{8}$ assume the third $\pi$ band at $13.9 \mathrm{eV}$. The presence of this band does not follow from the bandshape criterion because it is hidden under a number of $\sigma$ bands. In fact its presence can only be assumed on basis of calculations. However, in all three series we see this $\pi_{3}$ band emerge from the host of $\sigma$ bands when the degree of fluorination increases. In the pyrimidine series we see how the three $\pi$ and two $n$ bands finally become separately visible in tetrafluoropyrimidine. In general our analysis of the series supports the analysis of the parent compounds as given by Gleiter et al. ${ }^{8}$. 


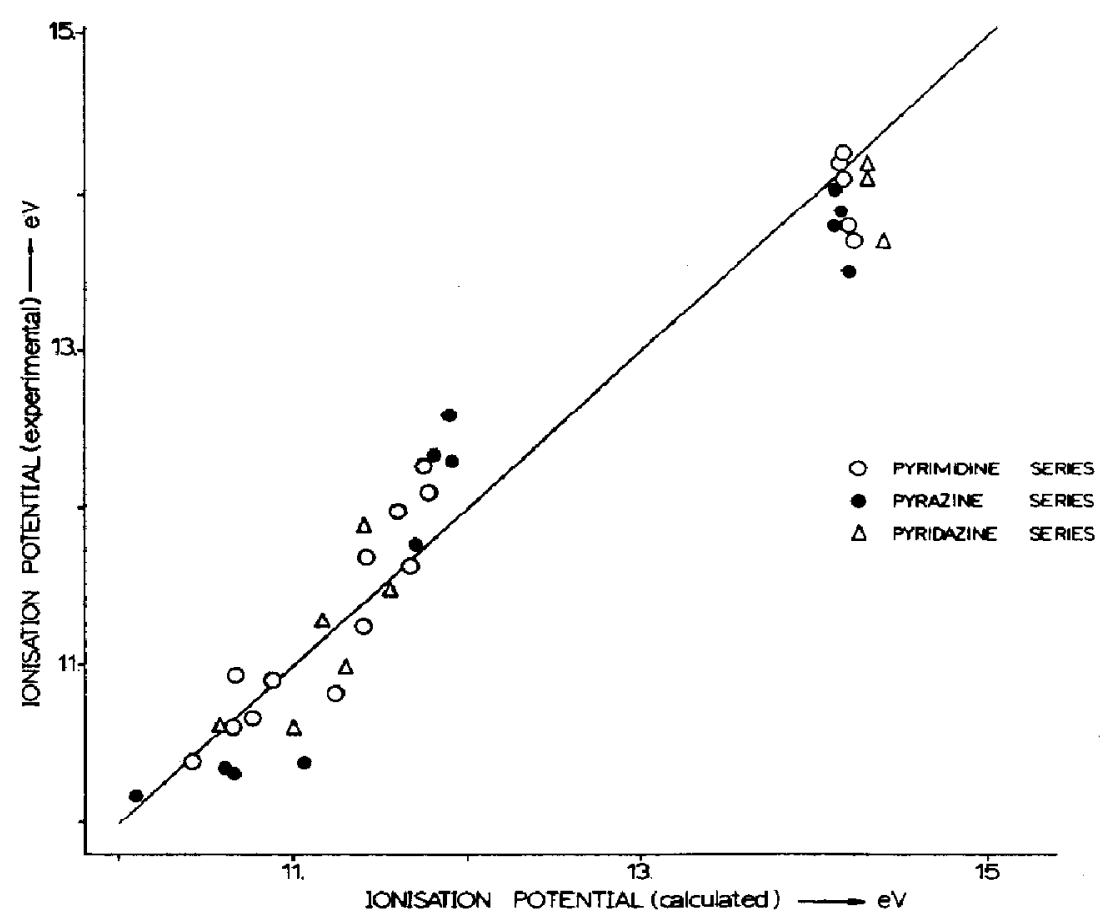

Figure 4. Correlation of experimental versus calculated $\pi$ ionization potentials.

Correlation of experimental and calculated $\pi$ ionization potentials

Previously we demonstrated ${ }^{3,4}$ that the effect of fluorine substitution could be described with Hückel calculations. A parameter set $\left(\alpha_{\mathrm{N}}=\alpha_{\mathrm{C}}+0.7 \beta_{\mathrm{CC}} ; \alpha_{\mathrm{C}(\mathrm{F})}=\right.$ $\left.\alpha_{\mathrm{C}}+0.6 \beta_{\mathrm{CC}} ; \alpha_{\mathrm{F}}=\alpha_{\mathrm{C}}+3.0 \beta_{\mathrm{CC}} ; \beta_{\mathrm{CC}}=\beta_{\mathrm{CN}} ; \beta_{\mathrm{CF}}=0.7 \beta_{\mathrm{CC}}\right)$ has been proposed, with which the $\pi$ energies of substituted and parent aza- and diazanaphthalenes could be predicted. We used the same parameter set to describe the $\pi$ system of the diazabenzene series. A plot of experimental $\pi$ ionization potentials (IP $(\pi)$ ) versus calculated $\operatorname{IP}(\pi)$ 's is presented in Figure 4.

\section{Correlation of experimental and calculated " $n$ " ionization potentials}

One of the differences between the PE spectra of the diazines and benzene is the occurrence of two $\sigma$ bands in the 9-12 eV region. These bands are usually called " $n$ " bands. In a simple valence-bond model they can be ascribed to the lone-pair orbitals of the nitrogen atom. Because benzene and the diazines are isoelectronic, these " $n$ " bands can also be considered as benzene $\sigma$ orbitals that have gained energy. This destabilization can be explained by the partial localization of these orbitals on the nitrogen centres.

It is not unreasonable to demand that in the results of all valence electron calculations this fact must be reflected in large atomic contributions of the nitrogen centres in the highest occupied $\sigma$ MO's. Support for this requirement is found in recent ab initio calculations for the diazines by Almlöf et al. ${ }^{12}$. In these calculations 


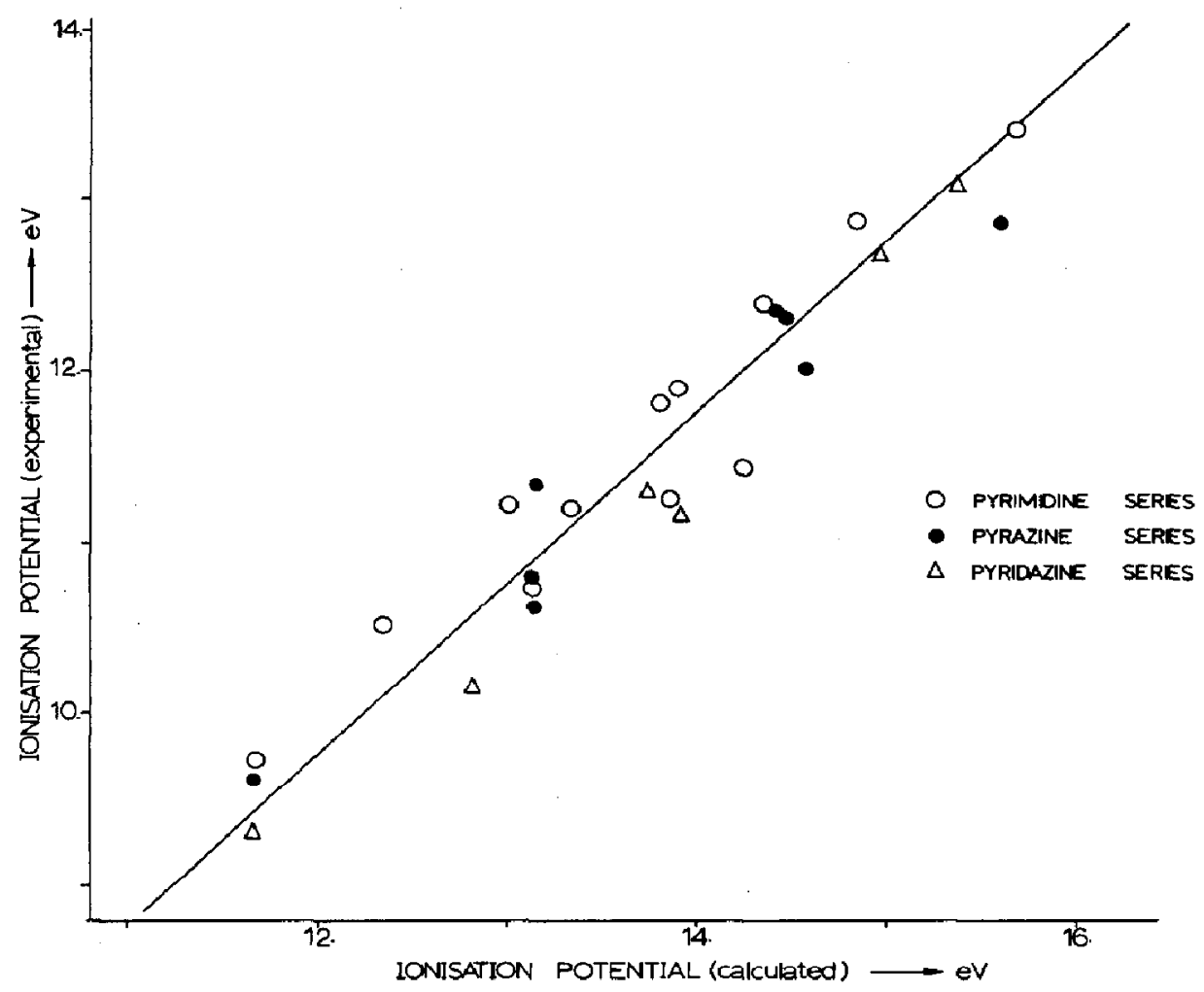

Figure 5. Correlation of experimental versus calculated "lone-pair" ionization potentials.

the lone-pair electrons are strongly localized ( $>60 \%$ ). Extended Hückel calculations (EH'T) also localize these electrons to a certain extent. We found this type of calculations useful for the prediction of the "lone-pair" splitting in the diazanaphthalene series $^{13}$. Recently an iterative and modified version of EHT (MIEHM) was proposed ${ }^{14}$. The results of this method for the aza- and polyazabenzenes are in accordance with those of Almlöf et al.

We calculated " $n$ " ionization potentials with MIEHM and found the results satisfactory (Figure 5). Values calculated with EHT, MIEHM and MEHM * (noniterative MIEHM) are collected in Table 2, together with the experimental IP(n) values and the predicted lone-pair orbital symmetries. All calculations were based on regular molecular geometries: $R(\mathrm{CC})=R(\mathrm{CN})=R(\mathrm{NN})=1.39 \AA ; R(\mathrm{CH})=$ $1.084 \AA ; R(C F)=1.360 \AA$. For the parameters used, we refer to refs. 4 and 14 .

The through-bond interaction model

For certain kinds of symmetrical heterocyclic molecules, containing more

\footnotetext{
^ The MIEHM/MEHM program was kindly supplied to us by Dr. J. Spanget-Larsen [Åarhus Denmark].
} 
than one hetero atom, the sign of the interaction energy of "lone-pair" orbitals can be visualized with the aid of the through-space and through-bond coupling model of Hoffmann et al..$^{5}$. As was shown before ${ }^{13}$ this model also offers a simple explanation for the influence of substituted fluorine on the energy levels of the symmetrical and antisymmetrical "lone-pair" combination in nitrogen heterocycles when the nitrogen atoms are separated by an odd number of $\sigma$ bonds.

As has been pointed out by Hoffmann et al. ${ }^{5}$, the results of the simple interaction model and those of EHT contradict one another for the pyrimidine case. Because es pecially MIEHM results correlate very well with the measured IP(n) values, these calculated data can be relied on. The interesting question remains why the simple model fails in this case. We hope to return to this question when we have studied the PE spectra of fluorine substituted 1,3-diaza-, 1,8-diaza-, and 2,7diazanaphthalene.

\section{ACKNOWLEDGEMENT}

We would like to thank Mr. J. Havekes for his assistance in the synthetical part of this work. We are greatly indebted to Prof. M. P. Groenewege and Dr. C. Worrell (University of Utrecht), who put their electron spectrometer at our disposal.

\section{REFERENCES}

1 C. R. Brundle, M. B. Robin and N. A. Kuebler, J. Amer. Chem. Soc., 94 (1972) 1466.

2 G. H. King, J. N. Murrell and R. J. Suffolk, JCS Dalton Trans., (1972) 564.

3 D. M. W. van den Ham and D. van der Meer, Chem. Phys. Lett., 15 (1972) 549.

4 D. M. W. van den Ham and D. van der Meer, J. Electron Spectrosc., 2 (1973) 247.

5 R. Hoffmann, A. Imamura and W. Hehre, J. Amer. Chem. Soc., 90 (1968) 1499.

6 D. W. Turner, C. Baker, A. D. Baker and C. R. Brundle, Molecular Photoelectron Spectroscopy, Wiley-Interscience, London, 1970.

7 C. Fridh, L. Åsbrink, B. Ö. Jonsson and E. Lindholm, Int. J. Mass Spectrom. Ion Phys., 9 (1972) 485 and references therein.

8 a R. Gleiter, E. Heilbronner and V. Hornung, Angew. Chem., 82 (1970) 878.

8b R. Gleiter, E. Heilbronner and V. Hornung, Helv. Chim. Acta, 55 (1972) 255.

9 R. D. Chambers, J. A. H. MacBride and W. K. R. Musgrave, J. Chem. Soc. C, (1968) 2118.

10 C. G. Allison, R. D. Chambers, J. A. H. MacBride and W. K. R. Musgrave, J. Chem. Soc. C, (1970) 1026.

11 R. E. Banks, D. S. Field and R. N. Haszeldine, J. Chem. Soc. C, (1967) 1822.

12 J. Almlöf, B. Roos, U. Wahlgren and H. Johansen, J. Electron Spectrosc, 2 (1973) 51.

13 D. M. W. van den Ham and D. van der Meer, Chem. Phys. Lett., 12 (1972) 477.

14 J. Spanget-Larsen, J. Electron Spectrose, 2 (1973) 33. 